\title{
Legionnaires' disease on an oil drilling platform in the Mediterranean: a case report
}

\author{
M CASTELLANI PASTORIS, ${ }^{1}$ D GRECO,${ }^{1} \mathrm{~J}$ M CACCIOTTOLO, ${ }^{2}$ A VASSALLO,${ }^{3}$ \\ A GRECH ${ }^{3}$ C L R BARTLETT ${ }^{4}$

\begin{abstract}
From the Istituto Superiore di Sanità, ${ }^{1}$ Rome, Italy, St Luke's Hospital ${ }^{2}$ and Department of Health, ${ }^{3}$ Valletta, Malta, and Public Health Laboratory Service, ${ }^{4}$ Communicable Disease Surveillance Centre, Colindale, London, UK
\end{abstract}

Legionella pneumophila, the aetiological agent of legionnaires' disease, appears to be ubiquitous in moist natural environments and has been found in non-disease associated natural waters, often in concentrations of 106 organisms/litre, at temperatures ranging from $5^{\circ}$ to $65^{\circ} \mathrm{C} .^{1-4}$

The investigation of outbreaks has shown that hot water systems in large buildings are the most important source of epidemic legionella infections but cooling water systems serving air conditioning equipment and whirlpool spas have also been implicated. Although the route of transmission has not always been determined, evidence for the role of inhalation of aerosolised contaminated water has often been obtained.

An oil drilling sea platform consitututes a fully isolated environment where healthy workers can come into contact with few potential sources of legionella: we report the investigation of a case in such an environment.

\section{Case history}

On 2 January 1986 a 27 year old man was admitted to St Luke's Hospital in Malta with high fever $\left(39^{\circ} \mathrm{C}\right)$, dyspnoea, and a rapid pulse. He gave a history of one week of illness with fever, weakness, and some episodes of watery diarrhoea. Although he was a heavy smoker ( 20 cigarettes/day), he had no history of respiratory diseases.

Chest $x$ ray films showed a diffuse opacity at the right upper and mid-pulmonary zones with faint mottling over the rest of the lungs. His condition worsened rapidly in the following days and he went into type I respiratory failure and was ventilated with positive pressure. No evidence of immunodeficiency was found. A presumptive diagnosis of legionnaires' disease was made and treatment with erythromycin was

Accepted 20 October 1986 begun. A few days later rifampicin was added to the treatment. Clinical recovery began two weeks later and the patient was discharged one month after admission in good condition.

Sera from the second and tenth days after admission sent to the division of microbiological reagents and quality control, Central Public Health Laboratory, at Colindale, London, had titres of 64 by indirect immunofluorescence test (IFA) and 32 by microagglutination (MA) for the first sample taken on 4 January and of 2048 (IFA) and 256 (MA) for the second sample collected on 12 January against $L$ pneumophila serogroup 1 antigens.

\section{Epidemiological investigations}

The patient, a Maltese citizen, had been working on a drilling platform operating about one mile from the southern coast of Sicily. Workers of different nationalities worked on continuous four to five week shifts. The patient had never landed during his shift period, which ended on 29 December. He worked 12 hours a day, alternating with 12 hours of rest, and with two breaks of one hour during the work period. His main function was to help with the drilling process, manually moving pipe tubes and periodically cleaning the equipment of mud which came from the hole. Cleaning was performed with a water gun spraying water from reservoirs on the platform.

Attention was focused on the water systems used on the platform. An installation for desalinising sea water supplied the water for domestic use (drinking, cooking, and washing, for example). The initial temperature of the "domestic" hot water was about $56^{\circ} \mathrm{C}$. In addition, water brought from land (Sicily) was used for cleaning the platform and the drilling apparatus. This "industrial" water shot forth from a pipe with great force, creating an aerosol. The median temperature of this water was constantly between $5^{\circ} \mathrm{C}$ and $10^{\circ} \mathrm{C}$. There was a cooling and a heating air conditioning system. 
During the same period 28 workers were present on the platform, none of whom declared any symptoms. Blood samples were taken from this cohort and none showed a significant antibody titre against $L$ pneumophila serogroup 1 antigens (less than 16 by IFA test).

\section{Bacteriological studies}

Desalinised water samples were collected into sterile containers from several parts of the domestic water distribution system and from the cold and hot water storage tanks. Samples of the industrial water were also taken from the tank and from the end of the pipe. All the samples were concentrated by filtration through Millipore (pore size $0.22 \mu$ ) and plated on to BCYE agar with and without GVPC selective supplement. ${ }^{5}$ The evaporative water from the air conditioned distribution system at the canteen was also checked.

The concentrated suspensions were also examined by direct immunofluorescent antibody (FA) test, using specific monovalent fluorescent antisera against $L$ pneumophila serogroups 1 to 8 provided by the Center for Disease Control, Atlanta, Georgia, USA. Repeated attempts failed to grow legionellae from any of the water samples. Nevertheless, the concentrated industrial water was positive for $L$ pneumophila serogroup 1 by direct FA assay (DFA).

\section{Discussion}

The reason that environmental contamination with $L$ pneumophila rarely causes infection in man is unclear although bacterial concentration, differences in virulence between the strains, and host susceptibility are some of the factors that may play a part in the process.

Heavy work duties, long working hours (12 consecutive hours a day), and prolonged exposure to aerosolised contaminated water could have played a part in the aetiology in this case, but the same conditions were shared by nine other workers, none of whom showed any clinical or serological signs of infection. Since the patient stayed on the platform for three weeks before the onset of symptoms, no other source of infection can be considered.

The epidemiological investigation and the sampling took place after the drilling company had performed a complete cleaning and chlorination of the water system on the platform; the only water that had not been chlorinated was the industrial water.

Possibly, therefore, the domestic hot or cold water systems may have served as the source of infection and no laboratory evidence was obtained to implicate them because of the extent of the cleaning and chlorination process. This is unlikely because experience elsewhere suggests that killed organisms at least 3 would be detected by means of DFA. Furthermore, $\stackrel{\mathbb{Q}}{\circ}$ water systems supplied with "desalinated" water have $\Rightarrow$ not been reported as sources of legionella infections. $\stackrel{\mathscr{S}}{\stackrel{9}{+}}$

The fact that there was microbiological evidence to indicate the presence of $L$ pneumophila serogroup 1 , 흠 the causative organism, in the industrial water to $\frac{\omega^{2}}{\Phi}$ which the worker had been exposed for prolonged $\stackrel{\varnothing}{\complement}$ periods suggests that this was the source of infection. The organism would not have multiplied actively at $\vec{\circ}$ the temperatures in which the industrial water was ${ }_{-}^{\circ}$ stored but would certainly have survived. It is not $\vec{\omega}$ known if exposure to relatively low concentrations of $\stackrel{\circ}{\circ}$ $L$ pneumophila serogroup 1 in aerosols over a long period of up to 12 hours would result in infection in a susceptible person. In this instance, the concentration + of the organism in the industrial water at the time the 6 worker contracted legionnaires' disease is not known. ? Possibly the water was heavily contaminated when it was supplied by the tanker to the platform.

Whatever the circumstances, this type of process $\vec{\sim}$ water should be considered as a potential source of $\mathbb{\Phi}$ legionellosis. Good engineering practices should be $\frac{\vec{D}}{\vec{D}}$ followed, therefore, in maintaining and operating the $\frac{\mathbb{D}}{3}$ reservoir, pipework, and related equipment to mini- $\mathbb{Q}$ mise the chances of legionella infection occurring among drilling platform workers.

We gratefully thank the AGIP Sicilian Company ar the Global Marine Adriatic IV platform staff, and Pre $S$ Ciriminna, Regional Health Authority, Sicily, for help given in the investigation.

Requests for reprints to: Dr M Castellani Pastoris, Bacteriology and Medical Micology, Istituto Superiore di Sanità, Viale Regina Elena, 299, 00161 Rome, Italy.

\section{References}

1 Fliermans CB, Cherry WB, Orrison LH, Smith SJ, Tison DL, Pope DH. Ecological distribution of Legionella pneumophila. Appl Environ Microbiol 1981;41:9-16

2 Kurtz JB, Bartlett CLR, Newton VA, White RA, Jones NL. Le- 음 gionella pneumophila in cooling water systems. Report of a $D$ survey of cooling towers in London and a pilot trial of selected 을. biocides. J Hyg 1982;88:369-81.

3 Tison DL, Baross JA, Seidler RJ. Legionella in aquatic habitats $\mathrm{N}$ in the Mount St Helens blast zone. Current Microbiology 1983;9:345-8.

4 Desplaces NK, Nahapetian K, Dournon E. Inventaire des Le- N gionella dans l'environnement Parisien: implications practiques. Presse Med 1984;13:1875-9.

5 Dennis PJ, Bartlett CLR, Wright AE. Comparison of isolation methods for Legionella spp. In: Thornsberry C, Balows A, (D) Feeley JC, Jakubowski W, eds. Legionella. Proceedings of the 2nd international symposium, Atlanta, Georgia, June 1983. Washington: American Society for Microbiology, 1984:294-6. 